\title{
Hidden Host Plant Associations of Soilborne Fungal Pathogens: An Ecological Perspective
}

\author{
Glenna M. Malcolm, Gretchen A. Kuldau, Beth K. Gugino, and María del Mar Jiménez-Gasco
}

Department of Plant Pathology and Environmental Microbiology, The Pennsylvania State University, University Park 16802. Current address of G. M. Malcolm: Department of Plant Science, The Pennsylvania State University, University Park 16802. Accepted for publication 31 December 2012.

\section{ABSTRACT}

Malcolm, G. M., Kuldau, G. A., Gugino, B. K., and Jiménez-Gasco, M. M. 2013. Hidden host plant associations of soilborne fungal pathogens: An ecological perspective. Phytopathology 103:538-544.

Much of the current knowledge on population biology and ecology of soilborne fungal pathogens has been derived from research based on populations recovered from plants displaying disease symptoms or soil associated with symptomatic plants. Many soilborne fungal pathogens are known to cause disease on a large number of crop plants, including a variety of important agronomical, horticultural, ornamental, and forest plants species. For instance, the fungus Verticillium dahliae causes disease on $>400$ host plants. From a phytopathological perspective, plants on which disease symptoms have not been yet observed are considered to be nonhosts for $V$. dahliae. This term may be misleading because it does not provide information regarding the nature of the plant-fungus association; that is, a nonhost plant may harbor the fungus as an endophyte. Yet, there are numerous instances in the literature where $V$. dahliae has been isolated from asymptomatic plants; thus, these plants should be con- sidered hosts. In this article, we synthesize scattered research that indicates that $V$. dahliae, aside from being a successful and significant vascular plant pathogen, may have a cryptic biology on numerous asymptomatic plants as an endophyte. Thus, we suggest here that these endophytic associations among $V$. dahliae and asymptomatic plants are not unusual relationships in nature. We propose to embrace the broader ecology of many fungi by differentiating between "symptomatic hosts" as those plants in which the infection and colonization by a fungus results in disease, and "asymptomatic hosts" as those plants that harbor the fungus endophytically and are different than true nonhosts that should be used for plant species that do not interact with the given fungus. In fact, if we broaden our definition of "host plant" to include asymptomatic plants that harbor the fungus as an endophyte, it is likely that the host ranges for some soilborne fungal pathogens are much larger than previously envisioned. By ignoring the potential for soilborne fungal pathogens to display endophytic relationships, we leave gaps in our knowledge about the population biology and ecology, persistence, and spread of these fungi in agroecosystems.
Endophytes are defined as organisms living inside plants that exhibit no visible symptoms as a result of this colonization (60) and generally include bacterial and fungal organisms. Endophytic relationships often go unnoticed due to the lack of symptomatology in the plant and are usually only discovered by examining internal tissues under a microscope, by aseptic isolation from plants, or from polymerase chain reaction (PCR) detection of microorganisms in DNA extracted from surface-disinfested plant tissues (67). Yet fungal endophytes, our focus in this article, are nearly ubiquitous across all groups of vascular plants, as documented by the extensive literature describing isolation and identification of these organisms $(2,61)$. There is also a significant biological diversity among fungal endophytes, and it is not rare for some plant species to host hundreds of different fungal endophytic species $(30,51,63)$, at least under tropical environments. Many of these endophytic fungi have been sought and characterized for their ability to produce biologically active secondary metabolites with potential uses in medicine, agriculture, and other areas (73).

Fungal endophytes are distinct from mycorrhizal fungi, which grow both inside and beyond the plant root system, whereas the growth of endophytes is limited to internal tissues of the plant. Defined in this way, endophytic fungi comprise a highly diverse group of species. Rodriguez et al. (63) categorized endophytic fungi into four classes: class 1, Clavicipitaceous; class 2, non-

Corresponding author: M. M. Jiménez-Gasco;

E-mail address: jimenez-gasco@psu.edu

http://dx.doi.org/10.1094/PHYTO-08-12-0192-LE

(C) 2013 The American Phytopathological Society
Clavicipitaceous fungi colonizing the entire plant; class 3, nonClavicipitaceous hyper-diverse fungi colonizing aerial plant tissues; and class 4, dark septate endophytes. The Clavicipitaceous endophytes of grasses (class 1) are the best-studied group of fungal endophytes, and fungi in this group belong to Epichloël Neotyphodium and related genera. These latter fungi exist in a highly specialized, co-evolved symbiosis as obligate endophytes of grasses, and confer a number of benefits on their hosts, including drought tolerance, pest and pathogen resistance, and alleviation of phosphorous deficiency $(50,65)$. These endophytes are best known for providing defense against herbivory associated with synthesis of various biologically active metabolites, such as alkaloids, which are also toxic to vertebrate herbivores $(11,13,34$, $43,65,78)$. It appears, however, that most fungal endophytes are more generalists and not obligate symbionts in their growth (63). Importantly, many of these endophytes, such as those in the genera Fusarium and Rhizoctonia, for example, are mainly known as plant pathogens; or, in genus Xylaria, as decay organisms of plants $(2,44,61)$. However, with much of the research focused on these organisms as plant pathogens, our comprehensive understanding of the role of these fungi in agroecosystems is incomplete.

Regarding plant disease in agricultural ecosystems, research on plant-fungus interactions has been essentially focused on plant pathogenicity, and studies on fungal endophytes have been largely limited to the development of biocontrol agents $(1,3,27)$, which sometimes target fungi traditionally considered pathogens (66). An alternative that has been poorly addressed is that these organisms may have a dual role: a pathogenic lifestyle on certain plants and an endophytic one on others. The fact that plant pathogens can be endophytes on other plants has important implica- 
tions, such as asymptomatic plants inadvertently serving as reservoirs of inoculum and potentially initiating epidemics in other crops (71), or even serving as sources of hidden diversity of plant-pathogenic species. Because most research conducted on soilborne fungi has focused on pathogens infecting important agricultural commodities, we still lack a thorough understanding of the true nature of the associations of these fungi with other plants and their environment. Certain questions remain largely unaddressed. What are the ecological roles of plant-pathogenic fungi in agroecosystems when not causing disease on host plants? What are host plants, anyway? Here, we aim to synthesize the literature that supports the concept that many plant-pathogenic fungi, with a specific emphasis on Verticillium dahliae as our case study, have a cryptic endophytic life in plants traditionally considered to be nonhosts. Our goal is to describe a novel, expanded view of the biology, spread, and persistence of this plant fungal pathogen-endophyte, and discuss some research needs to fill in the gaps in knowledge.

Redefining the concept of host plant for fungal pathogens. The term "host" in plant pathology has been traditionally focused on the presence of disease symptoms as a consequence of fungal infection and colonization, modulated by the environment. However, from an ecological perspective, a host plant refers to any plant that harbors a fungus, regardless of the presence of disease symptoms. If a plant is colonized by a fungal pathogen but shows no disease symptoms, it may be most appropriate to describe that plant as a host rather than a nonhost to embrace an ecological framework (60). Such conflict was early addressed by Whetzel (74) by proposing the use of "suscept" to refer to a plant susceptible to disease. Other terms used to refer to plants that harbor a pathogenic organisms in the absence of disease symptoms include "symptomless carriers" (36) or "tolerant" hosts $(10,62)$. In the rest of this article, we will examine reported instances of fungi (specifically $V$. dahliae) in endophytic relationships with plants that may also be pathogenic on a different plant species. Thus, we will differentiate between "symptomatic hosts" as plant species displaying visible disease symptoms as a consequence of fungal infection, versus "asymptomatic hosts," where fungal infection results in an endophytic relationship (Fig. 1A). The term "asymp- tomatic host" differs from "tolerant or resistant" symptomatic host (62), where fungal colonization inside the plant may result in varying degrees of disease symptoms from no disease to a reduction in severity. The varying degrees of disease symptoms observed on symptomatic hosts may be due to (i) pathogenic variability as a pathogen attribute, (ii) different levels of resistance in the plant, or (iii) a consequence of differential interactions between plant and pathogen genotypes (Fig. 1A). For example, the defoliating pathotype of $V$. dahliae had increased quantum virulence on cotton and olive when compared with the nondefoliating pathotype, regardless of host genotype (31). Also, under controlled conditions, isolates of $V$. dahliae from artichoke caused disease on artichoke, cardoon, eggplant, or watermelon but isolates from watermelon, muskmelon, and eggplant showed differential pathogenicity, depending on the host-isolate combination (6). Symptomatic hosts of V. dahliae seem to be limited to dicotyledonous plants, whereas the current range of asymptomatic host plants of $V$. dahliae is unknown but appears to be associated with cereals or monocotyledonous crops in general (Table 1).

Symptomatic host plants of $\boldsymbol{V}$. dahliae. By far, most of the literature on $V$. dahliae is from a plant-pathogenic perspective, and this role has been extensively addressed in various excellent reviews $(12,31,38,64)$. In brief, V. dahliae is an anamorphic Ascomycete mainly known as an important soilborne plant pathogen that survives in the soil for extended periods of time due to the production of microsclerotia (clusters of thick-walled, heavily melanized cells), the fungal resting structures $(12,31,38,59)$. Disease is the consequence of extensive colonization of the plant's vascular system, resulting in wilting and necrosis. There are $>400$ plants reported as hosts (sensu plant pathology), or symptomatic hosts (as defined herein) of $V$. dahliae $(38,59)$, all of which are dicotyledonous species and are important agricultural, ornamental, or forest plants.

Isolates of $V$. dahliae are considered host-adapted rather than host-specific (i.e., they are pathogenic on many hosts but are more virulent to the host from which they were isolated) $(6,8,23,33$, $39,41,64)$. V. dahliae populations have been studied extensively through vegetative compatibility tests, referring to the ability of isolates to undergo hyphal anastomosis and form a stable hetero-
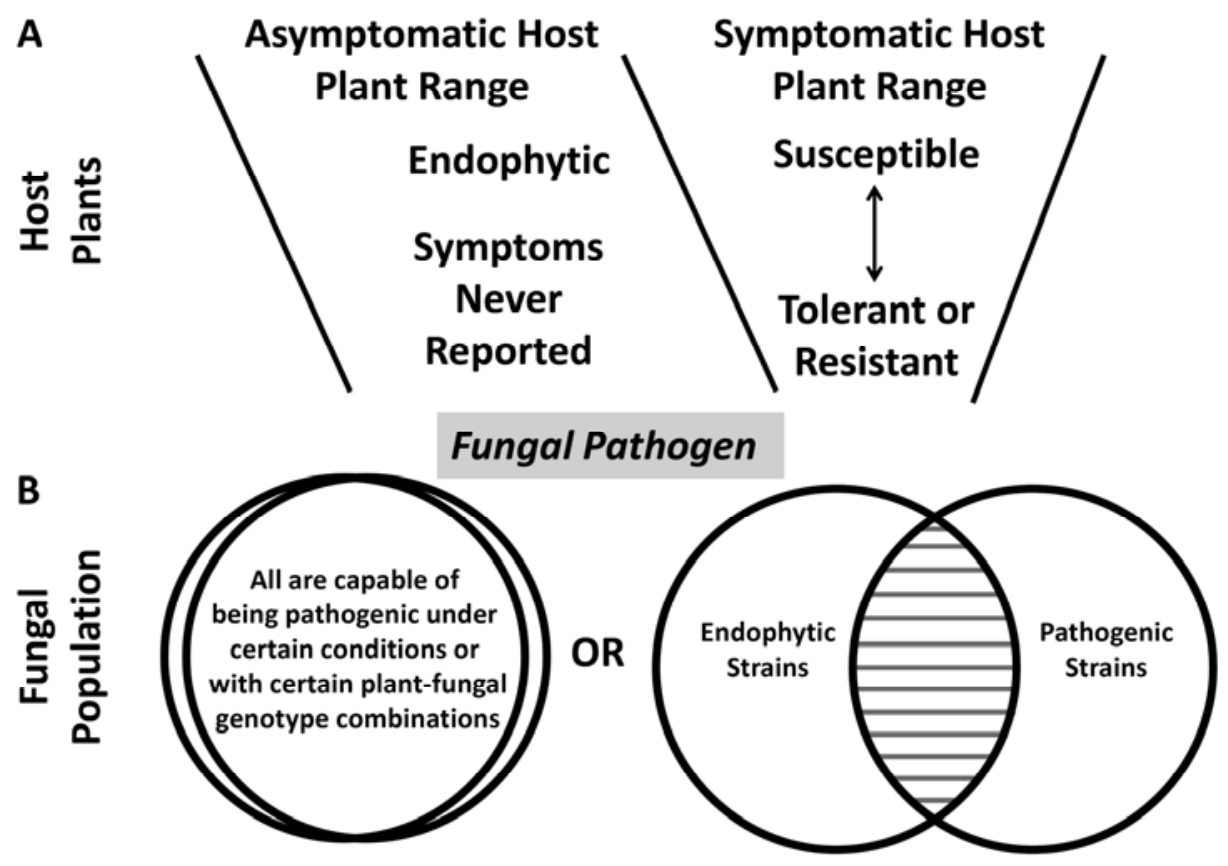

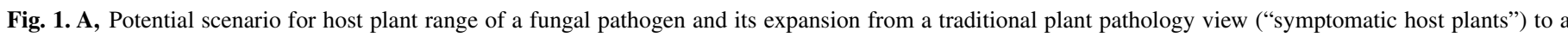

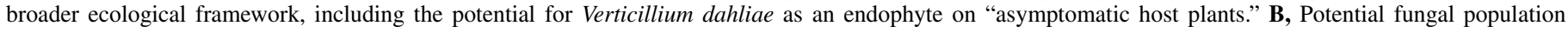

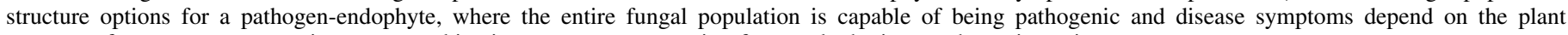
genotype-fungus genotype-environment combinations, or a spectrum exists from endophytic to pathogenic strains. 
karyon, and several vegetative compatibility groups (VCG) have been described $(33,37,64)$. In potato, populations corresponding to VCG $4 \mathrm{~A}$ are considered to be adapted to this crop $(58,64)$ and are also the most virulent of the two main VCGs (VCG 4A and VCG 4B) found associated with potato crops in the United States (64). However, other VCGs (2A and 2B) are associated with potato in other countries (5). These types of findings extend beyond potato crops. For instance, in Israel, VCG 2B isolates that originated from cotton were highly virulent on cotton and were less virulent on eggplant, but VCG $2 \mathrm{~B}$ isolates that originated from other plants were more virulent on eggplant than they were on cotton (41). All of these examples, taken together, indicate a certain degree of adaptation of specific populations (VCGs or specific genotypes) to particular plant hosts, even if, under controlled conditions, isolates are still pathogenic to plant species other than the one of origin $(6,32,79)$.
Asymptomatic host plants of $\boldsymbol{V}$. dahliae. In the scientific literature, observations of $V$. dahliae as an endophyte colonizing asymptomatic plant species have been documented. Many of these asymptomatic plants are cereal crops, used in crop rotations as part of management for Verticillium wilts, and weeds, which may be present in fields along with cultivated crops.

Associations between $V$. dahliae and monocot plants, although limited, result mostly from inoculation studies and not from field sampling (Table 1). In controlled experiments, Mol (55) inoculated several plant species with one isolate of $V$. dahliae from potato and did not observe any symptoms in barley and wheat. Significant amounts of microsclerotia, however, were observed in roots of barley compared with the limited amounts found in wheat roots. In greenhouse experiments using two $V$. dahliae isolates (one from potato and one from pea), Krikun and Bernier (42) inoculated several plant species, including the monocots wheat,

TABLE 1. Agricultural crops and common weed plant species found in endophytic relationships with Verticillium dahliae

\begin{tabular}{|c|c|c|c|c|}
\hline Scientific name & Common name & Type of study ${ }^{\mathrm{a}}$ & Tissues and observations ${ }^{b}$ & Reference \\
\hline \multicolumn{5}{|l|}{ Agronomic crops } \\
\hline Allium cepa & Onion & Root inoculation & Microsclerotia in roots & 49 \\
\hline \multirow[t]{4}{*}{ Avena sativa } & Oat & Field sampling & Stem isolation & This study \\
\hline & & Field sampling & Microsclerotia in ground foliage and stubble & 16 \\
\hline & & Soil inoculation & Stem isolation & 42 \\
\hline & & Root inoculation & Microsclerotia in roots & 29 \\
\hline \multirow[t]{4}{*}{ Hordeum vulgare } & Barley & Field sampling & Microsclerotia in ground foliage and stubble & 16 \\
\hline & & Soil and root inoculation & Microsclerotia in roots & 55 \\
\hline & & Soil inoculation & Stem isolation & 26,40 \\
\hline & & Root inoculation & Microsclerotia in roots & $29,46,54$ \\
\hline Secale cereale & Rye & Root inoculation & Microsclerotia in roots & 29 \\
\hline Sorghum bicolor & Sorghum & Soil inoculation & Stem isolation & 26 \\
\hline \multirow[t]{2}{*}{ Sorghum vulgare var. sudanense } & Sudangrass & Field sampling & Microsclerotia on foliage and stubble isolation & 16 \\
\hline & & Soil inoculation & Stem isolation & 26 \\
\hline Tulipa spp. & Tulips & Root inoculation & Microsclerotia in roots & 49 \\
\hline \multirow[t]{4}{*}{ Triticum aestivum } & Wheat & Field sampling & Microsclerotia on foliage and stubble isolation & 16 \\
\hline & & Soil inoculation & Root colonization & 45 \\
\hline & & Soil inoculation & Stem isolation & 26,42 \\
\hline & & Root inoculation & Microsclerotia in roots & $29,49,52,55$ \\
\hline \multirow[t]{3}{*}{ Zea mays } & Corn & Soil inoculation & Colonization of roots & 45 \\
\hline & & Soil inoculation & Stem isolation & 26 \\
\hline & & Root inoculation & Microsclerotia in roots & 29 \\
\hline \multicolumn{5}{|l|}{ Weeds } \\
\hline Amaranthus retroflexus & Redroot pigweed & Soil inoculation & Root, stem, and petiole isolation & 9 \\
\hline Bidens pilosa & Spanish needle & Field sampling & Stem isolation & 72 \\
\hline Calandrinea ciliata & Fringed redmaids & Field sampling & Stem isolation & 72 \\
\hline \multirow[t]{2}{*}{ Chenopodium album } & Common lambsquarter & Soil inoculation & Root, stem, and petiole isolation & 9,26 \\
\hline & & Field sampling & Stem isolation & 21,22 \\
\hline Cichorium intybus & Chicory & Soil inoculation & Root, stem, and petiole isolation & 9 \\
\hline Datura innoxia & Thornapple & Soil inoculation & Stem isolation & 26 \\
\hline Convolvulus arvensis & Field Bindweed & Field sampling & Stem isolation & 21,22 \\
\hline Erodium cicutareum & Redstem filaree & Field sampling & Stem isolation & 72 \\
\hline Lamium amplexicaule & Staggerweed & Field sampling & Stem isolation & 72 \\
\hline Malva neglecta & Common mallow & Soil inoculation & Root, stem, and petiole isolation & 9 \\
\hline Malva pusilis & Low mallow & Soil inoculation & Root, stem, and petiole isolation & 9 \\
\hline Malva sylvestris & Zebra mallow & Field sampling & Stem isolation & 72 \\
\hline Marrubium vulgare & White horehound & Soil inoculation & Stem isolation & 26 \\
\hline Medicago hispida & Bur clover & Field sampling & Stem isolation & 72 \\
\hline Medicago lupulina & Black medic & Soil inoculation & Root, stem, and petiole isolation & 9 \\
\hline Polygonum lapathifolium & Curlytop knotweed & Field sampling & Stem isolation & 21,22 \\
\hline Portulaca oleracea & Common purslane & Soil inoculation & Root, stem, and petiole isolation & 9 \\
\hline Salvia verbenaca & Wild sage & Soil inoculation & Stem isolation & 26 \\
\hline Silybum marianum & Milk thistle & Soil inoculation & Stem isolation & 26 \\
\hline Sinapis arvensis & Charlock mustard & Field sampling & Stem isolation & 21,22 \\
\hline \multirow[t]{2}{*}{ Solanum nigrum } & Black nightshade & Field sampling & Stem isolation & 72 \\
\hline & & Soil inoculation & Root, stem, and petiole isolation & 9 \\
\hline Tagetes elliptica & Mint marigold & Field sampling & Stem isolation & 72 \\
\hline Tagetes foeniculacea & Marigold & Field sampling & Stem isolation & 72 \\
\hline Tagetes multiflora & Marigold & Field sampling & Stem isolation & 72 \\
\hline Thiaspi arvense & Field pennycress & Soil inoculation & Root, stem, and petiole isolation & 9 \\
\hline
\end{tabular}

${ }^{a}$ Summary of the type of study conducted on the endophytic colonization of $V$. dahliae. Field sampling: plants collected in the field to either look for fungal structures or to isolate the fungus from surface-disinfested plant tissue. Soil inoculation: plants grown in soil or potting mix inoculated with microsclerotia from particular fungal isolates. Field soil: plants grown in soil collected from fields known to be infested with V. dahliae. Root inoculation: plants inoculated by root dipping in a V. dahliae conidial suspension.

b Summary of the tissues examined for endophytic colonization of $V$. dahliae and observations made by the authors of the study. 
barley, and oat. Those authors were able to recover the fungus growing asymptomatically in aboveground tissues but this depended on the plant species- $V$. dahliae isolate combination. For example, the potato isolate was not recovered from barley but was recovered from oat, whereas the pea isolate was obtained from barley but not from oat. Interestingly, these differential interactions may apply even to host genotypes within a given plant species because $V$. dahliae was only recovered from one wheat cultivar ('Glenlea') and not from another ('HY-320'). These results suggest that the endophytic relationship between monocots and $V$. dahliae may be highly specialized. Do these associations represent an initial stage of adaptation for pathogenicity to monocots, or are endophytic relationships with asymptomatic host plants stable? In 1986, a disease in barley was reportedly caused by $V$. dahliae $(53,54)$. However, Verticillium wilts in monocots have not been reported since then, indicating that, although the potential exists, $V$. dahliae isolates pathogenic on monocots may be rare. Overall, and based on the above studies, we can conclude that (i) $V$. dahliae has the ability to colonize monocot plant species endophytically and (ii) the endophytic interaction seems to be highly specialized and may depend on specific plant genotypefungus genotype interactions.

Another interesting group of plants that needs further consideration regarding endophytic relationships is weeds. Weeds are often incorporated into integrated disease management practices as reservoirs of pathogen inoculum; however, the potential of endophytic interactions between weeds and soilborne fungi serving as a pool of cryptic diversity has been somewhat ignored, likely due to their lack of agronomic value and to their pest status. In the case of weeds, numerous potential asymptomatic plantfungus associations with $V$. dahliae in field studies have been reported $(9,21,22,26,72)$ (Table 1$). V$. dahliae was isolated from lamb's quarters (Chenopodium album), common purslane (Portulaca oleraceae), and black nightshade (Solanum nigrum) in more than one of the above studies, which is suggestive that these weeds may commonly associate with the pathogen in many regions of the world. However, this tells us little about the frequency or the nature of the association in different weed populations. As a caveat, though, overlap exists between some of the weedy plant species described as symptomatic and as asymptomatic hosts for $V$. dahliae. For instance, $V$. dahliae was isolated from asymptomatic shepherd's purse plants (Capsella bursapastoris) (9) but wilting and chlorotic symptoms were observed on $C$. bursa-pastoris in a study examining weed hosts in Crete (48). Thus, it could be that some weed species are symptomatic hosts and their disease symptomology ranges from susceptible to resistant, whereas other weeds are true asymptomatic hosts. Unfortunately, in several studies, weeds were assessed as hosts for $V$. dahliae without distinguishing whether or not they showed disease symptoms, making it difficult to tease apart resistant symptomatic hosts from asymptomatic weed hosts $(21,22,35,71,75,77)$. Regardless of symptomatology, it is likely many of these weeds go unnoticed as hosts for the pathogen. These types of results highlight the need to understand the interactions between environment, fungal pathogen population biology, and location, to assess whether $V$. dahliae from weed plants are endophytic or pathogenic in nature, and to truly understand the breadth of this pathogen's host range.

A case study in Pennsylvania: association between $V$. dahliae and oats in fields with a history of Verticillium wilt of potato. Although a relationship between $V$. dahliae and oat was observed earlier in laboratory experiments (42), we had a unique opportunity to characterize the frequency of this association under field conditions in a situation with natural levels of fungal inoculum.

From field collections during the 2009 and 2010 growing seasons, we sampled $V$. dahliae from asymptomatic oats and, in 2010, plants from a hay mix (timothy [Phleum pretense], alfalfa [Medicago sativa], red clover [Trifolium pratense], and hairy chess [Bromus commutatus]) in different fields on a farm located in Schuylkill County, PA. These crops were grown in rotation with potato crops that had exhibited significant Verticillium wilt incidence and severity in previous years. V. dahliae was isolated using routine protocols that included a thorough surface disinfestation of the lower portion of plant stems with $2.5 \%$ commercial bleach $(6.15 \% \mathrm{NaOCl})$, followed by plating a $0.6-\mathrm{cm}$ stem fragment on semiselective NP-10 medium and incubation at room temperature. We followed this with repeated subculturing of the fungus until a pure culture was obtained and identified by morphological characteristics (59). The 2-year crop rotation sequence at this farm was potato (year 1) followed by fall-seeded oat which then was under seeded with the hay mix (year 2), then repeated with potato. The fields sampled varied in the disease incidence and severity observed over multiple previous years of potato crops.

In 2009, $30 \%$ of oat plants sampled at inflorescence stage from a field with high disease incidence were colonized by $V$. dahliae, as shown by isolation of the fungus from oat stems. At this time, microsclerotia were not visible on the young green plant tissues. Comparatively, in 2010, only 5 to $8 \%$ of early-growth stage oat plants $(\approx 15$ to $20 \mathrm{~cm}$ tall; low Verticillium wilt disease incidence fields) were colonized by $V$. dahliae (Fig. 2). It is likely that the lower frequency of $V$. dahliae colonization of oat in 2010 was due to the observed differences in disease pressure in the fields in previous potato crops (which was probably associated with differences in soil inoculum densities) and to differences in plant phenological stages at the time of sampling. For instance, in a laboratory study, oat, wheat, and barley had a higher incidence of pathogen colonization in older versus younger plants (42). In addition to sampling oat plants for $V$. dahliae colonization, in 2010 we also sampled 20 plants each from the hay mix, which included timothy grass, alfalfa, red clover, and hairy chess, from a field with historic high disease incidence in potato crops. $V$. dahliae was not isolated from any of the plants in the hay mix sampled (Fig. 2). Until shown otherwise, the plants in the hay mix could be considered nonhosts of $V$. dahliae. Oat, rather than being considered a nonhost of $V$. dahliae, meets criteria for being an asymptomatic host for this fungal pathogenic species. To put this in perspective, growers in Pennsylvania are recommended to achieve a plant population of 1.2 to 1.5 million spring oat plants per acre (28). If $5 \%$ of 1.2 million spring oat plants were colonized by $V$. dahliae, that would correspond to 60,000 plants colonized per acre; and if $30 \%$ of spring oat plants were colonized, it would

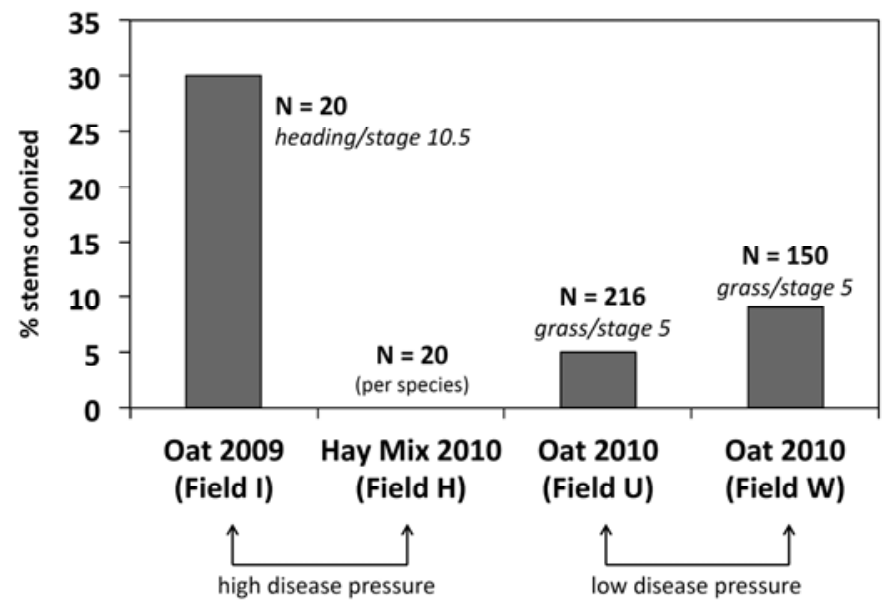

Fig. 2. Frequency of association between Verticillium dahliae and oat and hay mix (alfalfa, timothy, red clover, and hairy chess) plants sampled in fields previously planted to potato. Oat plants collected in 2009 were headed out in full flower, whereas oat plants collected in 2010 were in the last stages of tillering. Fields $\mathrm{I}$ and $\mathrm{H}$ had high incidence of Verticillium wilt in previous potato crops whereas fields $\mathrm{U}$ and $\mathrm{W}$ had low disease incidence. 
translate into 360,000 plants of oat colonized by $V$. dahliae per acre.

Supporting the notion that $V$. dahliae is recovered from monocot crops in the field, Davis and colleagues (17) reported that oat, wheat, barley, sudangrass, and field corn were colonized by $V$. dahliae but to a lesser degree than a susceptible potato cultivar. This report was based on the number of fungal CFU produced in plant tissue (17). Unfortunately, the data did not reveal how frequent the association was between these crops and $V$. dahliae in the fields (i.e., percentage of plants colonized by the fungus in a given area).

Managing the disease with a broadened ecological perspective: Why asymptomatic hosts matter. Fungal inoculum produced on diseased plants can persist in soil for a long period of time. As a consequence, the long-term management of Verticillium wilt remains a challenge $(12,31,38,64)$. Effective management of the disease has often required the use of soil fumigants with broad-spectrum biological activity, such as metam sodium or methyl bromide (64). Unfortunately, although crop cultivars with resistance to Verticillium wilt have been identified, their implementation has been limited in some cases because they often lack the very specific horticultural and processing characteristics sought by the industry. For example, for potato in the United States, mainly one cultivar, 'Russet Nugget', with resistance to Verticillium wilt has been released in the past 20 years (64). With the phase-out of soil fumigants and a lack of desirable cultivars with resistance to the disease, growers have been largely left with manipulating their crop rotations by selecting crop plants traditionally considered nonhosts as a way of managing this disease by reducing pathogen inoculum $(14,19)$, but have had limited success $(25,57,70,76)$.

Research addressing rotational crops and crop sequences, as well as the use of green manures to reduce Verticillium wilt of various crops has been extensive over the past two decades and has yielded inconsistent results, depending on fields or regions. Also, at least for potato, none of the studies characterized the population of $V$. dahliae established in those soils, and most of the work was conducted in experimental fields in Idaho, Maine, and Washington $(15,16,18,19,25,46,47)$. For example, Davis et al. $(15,16,18,19)$ repeatedly reported a reduction in Verticillium wilt incidence of potato grown in 2- to 3-year rotations that included monocotyledonous and green manure crops. Green manures generally included sudangrass (Sorghum vulgare var. sudanense), sweet corn (as either an annual rotation or a summer rotation, depending on the cropping region), and brassica crops $(4,47,68)$. However, most experiments by Davis and co-authors were done in the same research experiment center in Southern Idaho, and none characterized the $V$. dahliae target population $(15,18)$. A closer examination of the soil microbial community after two to three seasons of corn green manure concluded that, although Verticillium wilt was reduced in the subsequent potato crop, microsclerotia soil densities remained the same as before the incorporation of corn to soil, and an increase of Fusarium spp. was observed. The authors speculated on the effect of green manures in modifying soil microbial communities and their role in disease suppression (15). The same type of experiments done in Washington State concluded that 1-year rotations of sudangrass, green pea-sudangrass (same year), spring wheat, spring wheat-sudangrass (same year), sweet corn, and field corn had no effect on Verticillium wilt of potato grown subsequently, and no reduction of microsclerotia in soil was observed following the rotations (25).

Our overall conclusions from the above studies are twofold. First, rotation with monocotyledonous and green manure crops can potentially reduce Verticillium wilts; however, the inconsistency of results may possibly be due, in part, to the fact that many of these "nonhosts" may actually form endophytic associations with V. dahliae (Table 1). Second, in all studies, the compo- sition of the target $V$. dahliae population was virtually unknown; therefore, the effectiveness of specific crop rotations for disease management may be highly dependent on the pathogen population structure. So long as we ignore the potential for $V$. dahliae to form associations with asymptomatic plants, and understand the role that population structure plays in asymptomatic interactions, we may never be able to incorporate rotations effectively into management of Verticillium wilts.

Implications and research needs. Understanding the full potential of $V$. dahliae to colonize host plants, from asymptomatic to symptomatic, will broaden our view of this pathogen (Fig. 1A). From an applied stand point, a better understanding of relationships among cereal crops and $V$. dahliae may allow us to use crop rotations more effectively in efforts to reduce soil inoculum levels as an efficient management practice. Perhaps some cereal crops, or even cultivars of a given species, are not as readily colonized by $V$. dahliae, or the fungus produces less inoculum or microsclerotia with a lower inoculum potential, when colonizing an asymptomatic host than a symptomatic one or when colonizing different asymptomatic host species. From a different applied stand point, further research on weed associations with $V$. dahliae might be quite important, especially in the context of sustainable and organic agriculture, where weed populations may not be as negligible as they can be in conventional agricultural systems. It may be that particular weed species might be more of a concern than other species as potential reservoirs and sources of inoculum for $V$. dahliae.

To our knowledge, few studies exist that analyze the population structure of $V$. dahliae in asymptomatic host plants, limited to VCG typing of isolates obtained from weed plants $(21,22,40)$. Some interesting and relevant questions need to be addressed. Is there a separate portion of the population that colonizes asymptomatic hosts (i.e., endophytic) compared with symptomatic hosts (i.e., pathogenic) (Fig. 1B)? Or is the entire $V$. dahliae species capable of being an endophyte and a pathogen (Fig. 1B), depending on the plant species, under a certain set of environmental conditions in a particular location? The limited research available suggests that isolates of $V$. dahliae collected from asymptomatic plants are capable of colonizing symptomatic host plants and causing disease in controlled conditions $(21,22,42)$. Although these studies imply that $V$. dahliae can be an endophyte in one situation and a pathogen in another, additional research, particularly under field conditions, is clearly needed. Another important question to consider is whether these asymptomatic plant hosts are adequate reservoirs for $V$. dahliae in the absence of a symptomatic plant host. For example, are the amounts of microsclerotia produced in asymptomatic hosts similar to those produced in symptomatic ones? In other words, are asymptomatic hosts as suitable for survival of $V$. dahliae as hosts exhibiting disease? Inoculations of potato and several cereal species showed that significantly lower numbers of microsclerotia were found in aerial parts and roots of cereal crops in comparison with the host potato plant, suggesting that these asymptomatic plants may not be hosts as adequate as susceptible potato in the short term but, over time, the fungal population can be maintained within the environment to some degree $(17,20,49,52,55,56)$. However, we should be cautious; these are just a few studies conducted on a small set of asymptomatic host plants under laboratory conditions, making it hard to make extensive conclusions and justifying the need for more research.

More importantly, the significance of endophytic relationships between asymptomatic host plants and fungi otherwise known as plant pathogens may expand beyond $V$. dahliae. For example, the fungus Fusarium oxysporum, well known as a causal agent of vascular wilts on hundreds of important crops, is one of the most commonly encountered fungi in asymptomatic plants (44), yet this endophytic association has been poorly characterized. When analyzing endophytic $F$. oxysporum isolates associated with field- 
grown tomato collected from a field in Pennsylvania, populations associated with four tomato cultivars were significantly different, although populations from surrounding soil were not, suggesting a potential effect of host genotype on the composition of endophytic populations (J. E. Demers and M. M. Jimenez-Gasco, unpublished). This suggests that the endophytic interaction between $F$. oxysporum (and possibly other plant-pathogenic fungi) and asymptomatic hosts may be more complex than previously envisioned.

Finally, as for many soilborne fungal pathogens, new Verticillium wilt diseases are being reported in crops that were once considered to be nonhosts or minor symptomatic hosts of $V$. dahliae, such as cauliflower, horseradish, lettuce, or pepper (7, 24,69). These examples, together with the earlier report of a disease caused by $V$. dahliae in barley $(53,54)$, indicate that there may be more biological diversity in this species that our traditional phytopathogenic research focus has completely ignored and, therefore, is yet to be discovered. Do endophytic relationships offer opportunities for virulence evolution in plant-pathogenic fungi? More importantly, does this biological diversity hold keys to identifying mechanisms of pathogenesis in fungi? Addressing some of the issues we have raised in this article may help understand the complex plant-fungus relationships in agricultural systems that can potentially lead us to develop environmentally sustainable disease management practices.

\section{ACKNOWLEDGMENTS}

We thank the grower who graciously allowed us to sample potato and oat fields; E. Shin, S. Colihan, and J. Krocker for excellent technical support; and R. M. Jiménez-Díaz for critically reading the manuscript prior to submission.

\section{LITERATURE CITED}

1. Alabouvette, C. 1990. Biological control of Fusarium wilt pathogens in suppressive soils. Pages 24-43 in: Biological Control of Soil-borne Pathogens. D. Hornby, ed. CAB International, Wallingford, UK.

2. Bacon, C. W., and White, J. F., Jr., eds. 2000. Microbial Endophytes. Marcel Dekker, Inc., New York.

3. Bae, H., Roberts, D. P., Lim, H.-S. Strem, M. D., Park, S.-C., Ryu, C.-M., Melnick, R. L., and Bailey, B. A. 2011. Endophytic Trichoderma Isolates from tropical environments delay disease onset and induce resistance against Phytophthora capsici in hot pepper using multiple mechanisms. Mol. Plant-Microbe Interact. 24:336-351.

4. Berbegal, M., García-Jiménez, J., and Armengol, J. 2008. Effect of cauliflower residue amendments and soil solarization on Verticillium wilt control in artichoke. Plant Dis. 92:595-600.

5. Berbegal, M., Garzón, C. D., Ortega, A., Armengol, J., Jiménez-Díaz, R. M., and Jiménez-Gasco, M. M. 2011. Development and application of new molecular markers for analysis of genetic diversity in Verticillium dahliae populations. Plant Pathol. 60:866-877.

6. Berbegal, M., Ortega, A., Jiménez-Gasco, M. M., Olivares-García, C., Jiménez-Díaz, R. M., and Armengol, J. 2010. Genetic diversity and host range of Verticillium dahliae isolates from artichoke and other vegetable crops in eastern-central Spain. Plant Dis. 94:396-404.

7. Bhat, R. G., Smith, R. F., Koike, S. T., Wu, B.M., and Subbarao, K. V. 2003. Characterization of Verticillium dahliae isolates and wilt epidemics of pepper. Plant Dis. 87:789-797.

8. Bhat, R. G., and Subbarao, K. V. 1999. Host range specificity in Verticillium dahliae. Phytopathology 89:1218-1285.

9. Busch, L. V., Smith, E. A., and Njohelango F. 1978. Effect of weeds on value of rotation as a practical control for Verticillium wilt of potato. Can. Plant Dis. Surv. 58:61-64.

10. Chen, P., Lee, B., and Robb, J. 2004. Tolerance to a non-host isolate of Verticillium dahliae in tomato. Physiol. Mol. Plant Pathol. 64:283-291.

11. Cheplick, G. P., and Clay, K. 1988. Acquired chemical defenses in grasses: The role of fungal endophytes. Oikos 52:309-318.

12. Cirulli, M., Bubici, G., Amenduni, M., Armengol, J., Berbegal, M., Jiménez-Gasco, M. M., and Jiménez-Díaz, R. M. 2010. Verticillium wilt: a threat to artichoke production. Plant Dis. 94:1176-1187.

13. Clay, K., Hardy, T. N., and Hammond, A. M. 1985. Fungal endophytes of grasses and their effects on an insect herbivore. Oecologia 66:1-5.

14. Davis, J. R., Huisman, O. C., Everson, D. O., Nolte, P., Sorensen, L. H., and Schneider, A. T. 2010. Ecological relationships of Verticillium wilt suppression of potato by green manures. Am. J. Potato Res. 87:315-326.

15. Davis, J. R., Huisman, O. C., Everson, D. O., Nolte, P., Sorensen, L. H., and Schneider, A. T. 2010. The suppression of Verticillium wilt of potato using corn as a green manure crop. Am. J. Potato Res. 87:195-208.

16. Davis, J. R., Huisman, O. C., Everson, D. O., Schneider, A. T., and Sorensen, L. H. 1999. Suppression of Verticillium wilt with wheat and improved yield and quality of the Russet Burbank potato. Am. J. Potato Res. 76:254-254.

17. Davis, J. R., Huisman, O. C., Sorensen, L. H., and Schneider, A. T. 1997. Field studies comparing the susceptibility of various crops to colonization by Verticillium dahliae. Page 29 in: Proc. 7th Int. Verticillium Symp. Athens, Greece.

18. Davis, J. R., Huisman, O. C., Westermann, D. T., Everson, D. O., Schneider, A., and Sorensen, L. H. 2004. Some unique benefits with sudangrass for improved US \#1 yields and size of Russet Burbank potato. Am. J. Potato Res. 81:403-413.

19. Davis, J. R., Huisman, O. C., Westermann, D. T., Hafez, S. L., Everson, D. O., Sorensen, L. H., and Schneider, A. T. 1996. Effects of green manures on Verticillium wilt of potato. Phytopathology 86:444-453.

20. Davis, J. R., Pavek, J. J., and Corsini, D. L. 1983. A sensitive method for quantifying Verticillium dahliae colonization in plant tissue and evaluating resistance among potato genotypes. Phytopathology 73:10091014.

21. Demirci, E., and Genc, T. 2009. Vegetative compatibility groups of Verticillium dahliae isolates from weeds in potato fields. J. Plant Pathol. 91:671-676.

22. Demirci, E., and Genc, T. 2011. Vegetative compatibility groups of Verticillium dahliae isolates from weeds in potato fields. Correction. J. Plant Pathol. 93:757.

23. Douhan, L. I., and Johnson, D. A. 2001. Vegetative compatibility and pathogenicity of Verticillium dahliae from spearmint and peppermint. Plant Dis. 85:297-302.

24. Eastburn, D. M., and Chang, R. J. 1994. Verticillium dahliae: A causal agent of root discoloration of horseradish in Illinois. Plant Dis. 78:496498.

25. Easton, G. D., Nagle, M. E., and Seymour, M. D. 1992. Potato production and incidence of Verticillium dahliae following rotation to non host crops and soil fumigation in the state of Washington. Am. Potato J. 69:489-502.

26. Evans, G., and Gleeson, A.C. 1973. Observations on the origin and nature of Verticillium dahliae colonizing plant roots. Aust. J. Biol. Sci. 26:151161.

27. Fravel, D., Olivain, C., and Alabouvette, C. 2003. Fusarium oxysporum and its biocontrol. New Phytol. 157:493-502

28. Hall, M., Roth, G., and Lingenfelter, D. 2011. Part one: Crop and soils management. In: The Penn State Agronomy Guide. Penn State College of Agricultural Sciences, University Park.

29. Harrison, J. A. C., and Isaac, I. 1969. Survival of the causal agents of 'early dying disease' (Verticillium Wilt) of potatoes. Ann. Appl. Biol. 63:277-288.

30. Higgins, K. L., Coley, P. D., Kursar, T. A., and Arnold, A. E. 2011. Culturing and direct PCR suggest prevalent host generalism among diverse fungal endophytes of tropical forest grasses. Mycologia 103:247260.

31. Jiménez-Díaz, R. M., Cirulli, M., Bubici, G., Jiménez-Gasco, M. M., Antoniou, P. P., and Tjamos, E. C. 2012. Verticillium wilt, a major threat to olive production: Current status and future prospects for its management. Plant Dis. 93:304-329.

32. Jiménez-Díaz, R. M, Mercado-Blanco, J., Olivares-García, C., ColladoRomero, M., Bejarano-Alcázar, J., Rodríguez-Jurado, D., Giménez-Jaime, A., García-Jiménez, J., and Armengol, J. 2006. Genetic and virulence diversity in Verticillium dahliae populations infecting artichoke in eastern-central Spain. Phytopathology 96:288-298.

33. Joaquim, T. R., and Rowe, R. C. 1990. Reassessment of vegetative compatibility relationships among strains of Verticillium dahliae using nitrate-nonutilizing mutants. Phytopathology 80:1160-1166.

34. Johnson, M. C., Dahlman, D. L., Siegel, M. R., Bush, L. P., Latch, G. C. M., Potter, D. A., and Varney, D. R. 1985. Insect feeding deterrents in endophyte-infected tall fescue. Appl. Environ. Microbiol. 49:568-571.

35. Johnson, W. M, Johnson, E. K., and Brinkerhoff, L. A. 1980. Symptomatology and formation of microsclerotia in weeds inoculated with Verticillium dahliae from cotton. Phytopathology 70:31-35.

36. Katan, J. 1971. Symptomless carriers of the tomato Fusarium wilt pathogen. Phytopathology 61:1213-1217.

37. Katan, T. 2000. Vegetative compatibility in populations of Verticilliuman overview. Pages 69-86 in: Advances in Verticillium Research and Disease Management. E. C. Tjamos, R. C. Rowe, J. B. Heale, and D. R. Fravel, eds. American Phytopathological Society, St. Paul, MN.

38. Klosterman, S. J., Atallah, Z. K., Vallad, G. E., and Subbarao, K. V. 2009. Diversity, pathogenicity, and management of Verticillium species. Annu. 
Rev. Phytopathol. 47:39-62.

39. Koike, S. T., Subbarao, K. V., Davis, R. M., Gordon, T. R., and Hubbard, J. C. 1994. Verticillium wilt of cauliflower in California. Plant Dis. 78:1116-1121.

40. Korolev, N., Katan, J., and Katan, T. 2000. Vegetative compatibility groups of Verticillium dahliae in Israel: Their distribution and association with pathogenicity. Phytopathology 90:529-536.

41. Korolev, N., Pérez-Artés, E., Mercado-Blanco, J., Bejarano-Alcázar, J., Rodríguez-Jurado, D., Jiménez-Díaz, R. M., Katan, T., and Katan, J. 2008. Vegetative compatibility of cotton-defoliating Verticillium dahliae in Israel and its pathogenicity to various crop plants. Eur. J. Plant Pathol. 122:603-617.

42. Krikun, J., and Bernier, C. C. 1987. Infection of several crop species by two isolates of Verticillium dahliae. Can. J. Plant Pathol. 9:241-245.

43. Kuldau, G. A., and Bacon, C. 2008. Clavicipitaceous endophytes: Their ability to enhance grass resistance to multiple stresses. Biol. Control 46:57-71.

44. Kuldau, G. A., and Yates, I. E. 2000. Evidence for Fusarium endophytes in cultivated and wild plants. Pages 85-117 in: Microbial Endophytes. C. W. Bacon and J. F. White, eds. Marcel Dekker, Inc., New York.

45. Lacy, M. L., and Horner, C. E. 1966. Behavior of Verticillium dahliae in rhizosphere and on roots of plants susceptible resistant and immune to wilt. Phytopathology 56:427-430.

46. Larkin, R. P., Griffin, T. S., and Honeycutt, C. W. 2010. Rotation and cover crop effects on soilborne potato diseases, tuber yield, and soil microbial communities. Plant Dis. 94:1491-1502.

47. Larkin, R. P., Honeycutt, C. W., and Olanya, O. M. 2011. Management of Verticillium Wilt of potato with disease-suppressive green manures and as affected by previous cropping history. Plant Dis. 95:568-576.

48. Ligoxigakis, E. K., Vakalounakis, D. J., and Thanassoulopoulos, C. C. 2002. Weed hosts of Verticillium dahliae in Crete: Susceptibility, symptomatology and significance. Phytoparasitica 30:511-518.

49. Malik, N. K., and Milton, J. M. 1980. Survival of Verticillium in Monocotyledonous plants. Trans. Br. Mycol. Soc. 75:496-497.

50. Malinowski, D., Alloush, G. A., and Belesky, D. P. 2000. Leaf endophyte Neotyphodium coenophialum modifies mineral uptake in tall fescue. Plant Soil 227:115-126.

51. Marquez, S. S., Bills, G. F., Acuna, L. D., and Zabalgogeazcoa, I. 2011. Endophytic mycobiota of leaves and roots of the grass Holcus lanatus. Fungal Divers. 41:115-123.

52. Martinson, C. A., and Horner, C. E. 1962. Importance of nonhosts in maintaining the inoculum potential of Verticillium. (Abstr.) Phytopathology 52:742.

53. Mathre, D. E. 1986. Occurrence of Verticillium dahliae on Barley. Plant Dis. 70:981-981.

54. Mathre, D. E. 1989. Pathogenicity of an isolate of Verticillium dahliae form barley. Plant Dis. 73:164-167.

55. Mol, L. 1995. Formation of microsclerotia of Verticillium dahliae on various crops. Neth. J. Agric. Sci. 43:205-215.

56. Mol, L., and van Riessen, H. W. 1995. Effect of plant roots on the germination of microsclerotia of Verticillium dahliae: I. use of root observation boxes to assess differences among crops. Eur. J. Plant Pathol. 101:673-678.

57. Njoroge, S. M. C., Kabir, Z., Martin, F. N., Koike, S. T., and Subbarao, K. V. 2009. Comparison of crop rotation for Verticillium wilt management and effect on Pythium species in conventional and organic strawberry production. Plant Dis. 93:519-527.

58. Omer, M., Johnson, D. A., Douhan, L. I., Hamm, P. B., and Rowe, R. 2008. Detection, quantification, and vegetative compatibility of Verticillium dahliae in potato and mint production soils in the Columbia Basin of Oregon and Washington. Plant Dis. 92:1127-1131.
59. Pegg, G. F., and Brady, B. L. 2002. Verticillium Wilts. CAB International, Wallingford, UK.

60. Petrini, O. 1991. Fungal endophytes of tree leaves. Pages 179-187 in: Microbial Ecology of Leaves. J. H. Andrews and S. S. Hirano, eds. Springer-Verlag, New York.

61. Redlin, S. C., and Carris, L. M. 1996. Endophytic Fungi in Grasses and Woody Plants. American Phytopathological Society, St. Paul, MN.

62. Robb, J. 2007. Verticilllium tolerance: Resistance, susceptibility, or mutualism? Can. J. Bot. 85:903-910.

63. Rodriguez, R. J., White, J. F., Jr., Arnold, A. E., and Redman, R. S. 2009. Fungal endophytes: diversity and functional roles. New Phytol. 182:314330.

64. Rowe, R. C., and Powelson, M. L. 2002. Potato early dying: Management challenges in a changing production environment. Plant Dis. 86:11841193.

65. Schardl, C. L., Leuchtmann, A., and Spiereing, M. J. 2004. Symbioses of grasses with seedborne fungal endophytes. Annu. Rev. Plant Biol. 55:315340.

66. Shittu, H. O., Castroverde, D. C. M, Nazar, R. N., and Robb, J. 2009. Plant-endophyte interplay protects tomato against a virulent Verticillium. Planta 229:415-426.

67. Stone, J. K., Bacon, C. W., and White, J. F. 2000. An overview of endophytic microbes: Endophytism defined. Pages 139-154 in: Microbial Endophytes. C. W. Bacon and J. F. White, eds. Marcel Dekker, Inc., New York.

68. Subbarao, K. V., and Hubbard, J. C. 1996. Interactive effects of broccoli residue and temperature on Verticillium dahliae microsclerotia in soil and on wilt of cauliflower. Phytopathology 86:1303-1310.

69. Subbarao, K. V., Hubbard, J. C., Greathead, A. S., and Spencer, G. A. 1997. Verticillium wilt. Pages 26-27 in: Compendium of Lettuce Diseases. R. M. Davis, K. V. Subbarao, R. N. Raid, and E. A. Kurtz, eds. The American Phytopathological Society, St. Paul, MN.

70. Subbarao, K. V., Kabir, Z., Martin, F. N., and Koike, S. T. 2007. Management of soilborne diseases in strawberry using vegetable rotations. Plant Dis. 91:964-972.

71. Vallad, G. E., Bhat, R. G., Koike, S. T., Ryder, E. J., and Subbarao, K. V. 2005. Weedborne reservoirs and seed transmission of Verticillium dahliae in lettuce. Plant Dis. 89:317-324.

72. Vargas-Machuca, R., Martin, C., and Galindez, W. 1987. Recovery of Verticillium dahliae from weed plants in farmers fields in Peru. Plant Dis. 71:756-758.

73. Wang, Y., and Dai, C.-C. 2011. Endophytes: A potential resource for biosynthesis, biotransformation, and biodegradation. Ann. Microbiol. 61:207-215.

74. Whetzel, H. H. 1929. The terminology of phytopathology. Pages 12042015 in: Proc. Int. Congr. Plant Sci. 2nd, Ithaca, NY.

75. Wooliams, G. E. 1996. Host range and symptomatology of Verticillium dahliae in economic, weed, and native plants in interior British Columbia. Can. J. Plant Sci. 46:661-669.

76. Xiao, C. L., Subbarao, K. V., Schulbach, K. F., and Koike, S. T. 1998. Effects of crop rotation and irrigation on Verticillium dahliae microsclerotia in soil and wilt in cauliflower. Phytopathology 88:10461055.

77. Yildiz, A., Doğan, N. M., Boz, Ö., and Benlioğlu, S. 2009. Weed hosts of Verticillium dahliae in cotton fields in Turkey and characterization of V. dahliae isolates from weeds. Phytoparasitica 37:171-178.

78. Zabalgogeazcoa, I. 2008. Fungal endophytes and their interaction with plant pathogens. Span. J. Agric. Res. 6:138-146.

79. Zeise, K., and Von Tiedemann, A. 2002. Host specialization among vegetative compatibility groups of Verticillium dahliae in relation to Verticillium longisporum. J. Phytopathol. 150:112-119. 